\title{
Awareness of obstetricians for long-term risks in women with a history of preeclampsia or HELLP syndrome
}

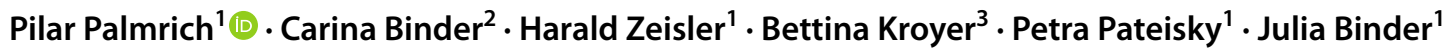

Received: 5 January 2021 / Accepted: 4 August 2021 / Published online: 18 August 2021

(c) The Author(s) 2021

\begin{abstract}
Purpose Hypertensive disorders of pregnancy are still a leading cause of maternal and neonatal morbidity and mortality worldwide. Women with a history of preeclampsia have an increased risk for future cardiovascular and cerebrovascular disease, renal disease as well as diabetes mellitus. There is little knowledge on postpartum risk management. The aim of this study was to assess follow-up care for patients after pre-eclampsia or HELLP syndrome.

Methods This questionnaire-based cross-sectional study aimed to evaluate the current recommendations of obstetricians in Austria regarding follow-up care, long-term risk counselling and risk of recurrence in future pregnancies after preeclampsia or HELLP syndrome. Data were collected using a survey, based on recommendations given by three substantial guidelines on hypertensive disorders of pregnancy, which was distributed via e-mail to 69 public obstetric departments in Austria. Each obstetric department was required to answer one questionnaire per local protocol.

Results Our results revealed that of the 48 participating hospitals most obstetricians are aware of the importance of followup care for women after a pregnancy complicated by preeclampsia. Our data show that most physicians counselled patients about the future cardiovascular health risks associated with preeclampsia or HELLP syndrome (79.2\%). Most obstetricians recommended lifestyle modification (77.1\%) and continued blood pressure measurements (97.9\%). All centers stated to counsel about the risk of recurrence $(100 \%)$. However, counselling regarding follow-up care to exclude kidney damage (37.5\%) and underlying diseases like thrombophilia (39.6\%) were less prioritized.

Conclusions We were able to show that counselling concerning the risk of long-term cardiovascular disease and risk of recurrence after a pregnancy complicated by preeclampsia or HELLP syndrome has been established in obstetric departments in public hospitals. Regarding the evaluation of underlying chronic diseases such as thrombophilia or renal disease, as well as counselling on the future risk of renal disease is still improvable according to our data. Further evaluation of follow-up care after hypertensive disorders of pregnancy in the outpatient and private sector and implementation of structured guidelines for follow-up, as well as screening for cardiovascular disease are necessary to ensure adequate risk management and to provide opportunities for prevention.
\end{abstract}

Keywords Pregnancy $\cdot$ Preeclampsia $\cdot$ Hypertensive disorders of pregnancy $\cdot$ Cardiovascular disease

Abbreviations
CVD
HDP

Cardiovascular disease

Hypertensive disorders or pregnancy

Pilar Palmrich

pilar.palmrich@meduniwien.ac.at

1 Department of Obstetrics and Feto-Maternal Medicine, Medical University of Vienna, Vienna, Austria

2 Department of Pathology, Medical University of Vienna, Vienna, Austria

3 Center for Medical Statistics, Informatics and Intelligent Systems, Medical University of Vienna, Vienna, Austria
HELLP syndrome Hemolysis, elevated liver enzymes and low platelets syndrome PE Preeclampsia

\section{Introduction}

Cardiovascular disease (CVD) is the most prevalent cause of death in women worldwide [1]. Hypertensive disorders of pregnancy (HDP), such as preeclampsia (PE), are known to be contributing factors to the risk of CVD [2,3], affecting $5-10 \%$ of pregnancies in the developed world [4]. HDP have been the leading cause of maternal and neonatal morbidity 
and mortality worldwide in the last decades. PE is a pregnancy-specific disorder defined by new-onset hypertension during pregnancy and at least one additional new-onset organ manifestation including proteinuria, thrombocytopenia, increased liver enzymes, neurological symptoms such as heachaches with visual disturbances, right upper quadrant abdominal pain and/or placental insufficiency manifesting in intrauterine growth restriction. Superimposed preeclampsia is defined as the new onset of one or more of the above features of preeclampsia occurring in addition to chronic hypertension during pregnancy [5]. Hemolysis, elevated liver enzymes and low platelets syndrome (HELLP syndrome) is a pregnancy-specific disorder characterized by increased transaminases, reduced platelet counts and hemolysis [5]. The underlying pathophysiology and pathomechanisms leading to PE are not yet fully understood. Multiple pathogenetic mechanisms have been suggested in this disorder, however, the common hypothesis implicats an underlying imbalance between angiogenic and antiangiogenic factors deriving from placental malperfusion and oxidative stress as a result of abnormal placentation [6,7] as well as more recently a cardiovascular origin of the disease was suggested [5-7]. Even though the clinical manifestation of PE commonly ceases within few days after delivery, studies on maternal hemodynamic changes in women with HDP revealed persistent long-term cardiac alterations of up to 2 years after $\mathrm{PE}$ and increased lifetime risk of essential hypertension, cardiovascular disease and stroke [8-10], disturbances in renal function [11] as well as increased risk of developing diabetes [12]. It has also been shown that women with a history of PE have an up to five- to 12-fold increased risk of developing end-stage renal disease later in life $[11,13]$. The association between PE and future CVD is no surprise given the fact that several studies have revealed that women with $\mathrm{PE}$ are in a state of cardiac dysfunction [5, 14]. PE has been shown to be associated with cardiovascular changes such as a decrease in cardiac output, increased systemic vascular resistance and left ventricular diastolic dysfunction [5, 6, 14, 15]. Studies on maternal hemodynamic changes in women with PE revealed persistent long-term cardiac alterations of up to two years after PE and increased lifetime risk of essential hypertension and cardiovascular disease [9]. Long-term follow-up studies have revealed a particularly high lifetime risk to develop cardiovascular disease as well as significantly higher cardiovascular mortality in cases of early-onset PE compared to women with a history of late-onset PE [2, 8, 10]. Additionally, women with a history of HDP have an increased risk of recurrence, with reported recurrence rates of more than $20 \%$ [16]. The overwhelming evidence that the obstetric history, particularly history of HDP, offers a unique risk marker to identify young women at risk for future cardiovascular and renal disease, has resulted in the incorporation of PE and HELLP syndrome (Hemolysis Elevated
Liver Enzymes Low Platelet Syndrome) as a female-specific risk factor in several guidelines, such as the 2011 American Heart Association guideline for prevention of CVD, the 2014 American Heart Association stroke prevention guideline and the 2016 European Society of Cardiology guideline CVD prevention [17-20]. Adequate screening and preventive measures, therefore, are key in this young population of women at risk of future cardiovascular and renal disease. However, information on the expertise of obstetricians and the quality of their counselling regarding postpartum management for patients after HDP is scarce. Current recommendations in Austria cover counselling on long-term risk for cardiovascular disease, risk of recurrence and lifestyle modifications as well as education on prevention in future pregnancies. Concerning follow-up after PE, the current guideline [21] recommends evaluation of secondary causes of hypertensive pregnancy complications at 3-6 months after delivery, including assessment of blood pressure, heart rate, BMI, urin status, laboratory assessments such as lipid profile and serum electrolytes, and assessment of kidney damage. Furthermore, recommendations include assessment of thrombophilia in severe cases and echocardiography in persistent hypertension. Currently, the recommendations regarding screening after PE include investigation of other cardiovascular risk factors and review of blood pressure, fasting glucose, BMI, and lipid status at regular intervals (at least every 5 years) [21]. Considering the significance of this issue, we aimed to assess the quality of follow-up care for patients after pre-eclampsia or HELLP syndrome.

\section{Material and methods}

This study was designed as a cross-sectional study to evaluate the follow-up care for patients after PE or HELLP syndrome in Austria. The data were collected using a questionnaire-based survey. The questionnaire was distributed via e-mail to all 69 public obstetric departments in Austria. As the study was designed as a cross-sectional study only one questionnaire per obstetric department was required to be returned. Participants were selected by the head of each department and asked to answer according to their local protocol. Returned questionnaires were filled in anonymously.

\section{Questionnaire}

The questionnaire was developed at the Department of Obstetrics and feto-maternal Medicine at the Medical University of Vienna. It was designed after research of current literature regarding follow-up care of patients affected by PE or HELLP syndrome based on guidelines from three different institutions, the National Institute for Health and Care Excellence, American College of Obstetrics and 
Gynaecologists and Arbeitsgemeinschaft der Wissenschaftlichen Medizinischen Fachgesellschaften in Germany [21-23]. The questionnaire consists of 17 questions divided into four sections covering sociodemographic data, longterm risk of cardiovascular disease and kidney damage after $\mathrm{PE}$, diagnostics of underlying disorders such as antiphospholipid syndrome or systemic lupus erythematosus, and risk of recurrence. The primary outcome of the study was to evaluate the follow-up care for patients after PE or HELLP syndrome, specifically assessing counselling on long-term risk of cardiovascular and renal disease, risk of recurrence of HDP as well recommendations on follow-up care including recommendations on postpartum diagnostics of possible underlying disease.

\section{Comparison of the guidelines}

In Table S1 we present the three guidelines [21-23] with regards to the questions in our survey. Questions 1-3 assessed age, gender and location of the clinic. Question 4 was eliminated to ensure the data privacy of the study participants.

\section{Statistical analysis}

For descriptive purposes, a table analyzing the study participants' county of origin (with reference to Austria) by gender (female, male, not mentioned) was generated, listing both the absolute and relative frequencies. Continuous variables were represented as median and interquartile range or mean and standard deviation depending on distribution assumptions. Categorical variables were represented as number and percentage of the total. Chi-squared test was used for group comparisons. For the number of recommendations, a $t$-test was fit to compare the medians, resulting in $p$-values, respectively. To illustrate the absolute and relative frequencies of the outcome tables were created for each question of the questionnaire.

\section{Results}

The questionnaire was sent to all 69 public obstetrical departments of which 48 participated in the survey (69.6\%). The median number of questions on possible recommendations answered with yes was 6 (IQR 3 [95\% CI 5.85-6.39]) of 9 questions (70.6\%). There was no difference in the median number of recommendations (median 6, IQR 3) between male and female participants $(p=0.690)$. Due to the small sample size, no statistically significant difference in dichotomised age, gender and region was found in regard to any of the sections of the questionnaire.

\section{Long-term risk of cardiovascular disease and renal disease}

Our survey showed that 38 centers $(79.17 \%)$ claimed to inform patients about future cardiovascular risks, while ten participants $(20.83 \%)$ stated that patients after PE or HELLP syndrome are not counselled on this topic at their department (see Fig. 1, Table S2). Only 18 departments (37.5\%) claimed to conduct consultation on long-term risk of renal disease (see Fig. 1). Regarding the timing of assessment of renal function, 10 of the participants that stated to consult on this issue suggested assessment at 3 months postpartum (20.83\%), 5 recommended assessment at 6 weeks postpartum (10.42\%), one participant recommended assessment at 3-6 months after delivery
Fig. 1 Recommendations on long-term risk counseling and diagnostics of underlying diseases. Percentages of participants recommending long-term risk assessment of cardiovascular disease, renal disease as well as screening for Diabetes mellitus Type II and screening for thrombophilia, as presented in Table 1. The $x$-axis shows (1) long-term risk assessment of cardiovascular disease (2) long-term risk assessment of renal disease (3) screening for Diabetes mellitus Type II

(4) Screening for thrombophilia. The $y$-axis represents the percentage of participants answering yes/no (where $n=48$ in all cases)

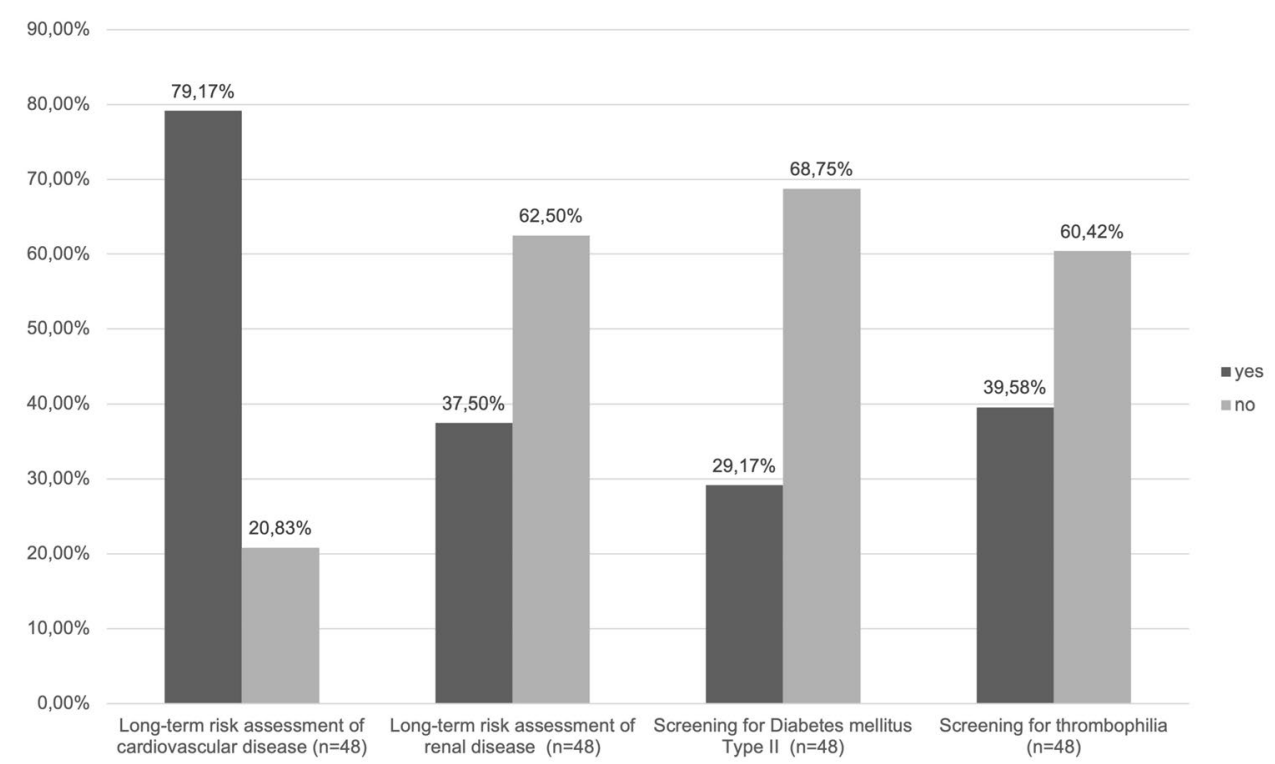


$(2.08 \%)$, one at 6 weeks and 3 months $(2.08 \%)$ and one recommended lifetime follow-up for the patient and for the child up until the age of 18 (see Table S2).

\section{Screening for underlying diseases}

Of all 48 centers, $29(60.42 \%)$ negated a recommendation for thrombophilia screening while 19 participants (39.6\%) recommended it, as shown in Table S2. Of those recommending thrombophilia diagnostics in their followup protocol, 8 recommended assessment in all cases of PE or HELLP syndrome (16.67\%), while 5 (10.42\%) recommended assessment only in severe cases. 14 Centers (29.17\%) stated to recommend diagnostics to exclude Type II Diabetes mellitus after PE or HELLP syndrome, of which $8(16.67 \%)$ recommended screening in every case and $5(10.42 \%)$ recommended assessment only in severe cases (see Fig. 1, Table S2). 33 departments (68.75\%) stated that follow-up recommendations do not include screening for diabetes mellitus at their department.

Table 1 Consultation before further pregnancy-recommendations on who should conduct a preconceptional assessment

\begin{tabular}{lrll}
\hline & $n$ & $\%$ & $\%$ of the cases \\
\hline Consultation before further pregnancy & & & \\
$\quad$ Internal medicine specialist & 11 & 16.92 & $22.92 \%$ \\
Hospital & 4 & 6.15 & $8.33 \%$ \\
General practitioner & 2 & 3.08 & $4.17 \%$ \\
Obstetrician & 46 & 70.77 & $95.83 \%$ \\
Specialist & 2 & 3.08 & $4.17 \%$ \\
Not recommended & 0 & 0 & - \\
Total & 65 & 100 & - \\
\hline
\end{tabular}

\section{Risk of recurrence, consultation before further pregnancies and yearly assessments}

According to the survey, all 48 of the participating obstetric departments $(100 \%)$ are consulting patients on the risk of recurrence after HDP. Additionally, all of the 48 participating centers $(100 \%)$ recommended conduction of a preconceptional visit before further pregnancies after HDP. See in Table 1 the recommendations on who should preferably conduct a preconceptional consultation. 14 participants gave more than one answer specifying who should conduct this consultation. On the basis of our questionnaire we determined how many of the participating centers recommend yearly assessment of blood pressure, blood glucose, blood lipids, BMI and serum creatinine (see Table 2).

\section{Life-style modification}

The majority of centers $(n=37,77.08 \%)$ are consulting patients after HDP on lifestyle modifications (regular exercise, healthy diet, if necessary, weight loss and smoking cessation), while 11 centers (22.92\%) stated to not consult patients on this issue.

\section{Postpartum blood pressure monitoring}

47 of 48 departments (97.92\%) reported to advise patients to continue blood pressure measurements and documentation after hospital discharge. Concerning the duration of postpartum blood pressure measurements, all answers were categorized into similar groups, shown in Table 3.

\section{Discussion}

This questionnaire-based, cross-sectional study aimed to evaluate the current recommendations of obstetricians in Austria regarding follow-up care, long-term risk counselling and risk of recurrence of HDP in future pregnancies after PE or HELLP syndrome. The basis of the survey was formed by
Table 2 Recommendations about yearly assessment of blood pressure, blood glucose, blood lipids, BMI and serum creatinine

\begin{tabular}{|c|c|c|c|c|c|c|}
\hline & \multicolumn{2}{|l|}{ Yes } & \multicolumn{2}{|l|}{ No } & \multicolumn{2}{|c|}{ Not mentioned } \\
\hline & $n$ & $\%$ & $n$ & $\%$ & $n$ & $\%$ \\
\hline \multicolumn{7}{|l|}{ Yearly assessments } \\
\hline $\begin{array}{l}\text { Total (at least one recom- } \\
\text { mendation) }\end{array}$ & 36 & 75 & 12 & 25 & - & - \\
\hline Blood pressure & 36 & 75 & 12 & 25 & 0 & $0 \%$ \\
\hline Blood glucose & 17 & 35.42 & 24 & 50 & 7 & $14.58 \%$ \\
\hline Blood lipids & 15 & 31.25 & 26 & 54.17 & 7 & $14.58 \%$ \\
\hline BMI & 19 & 39.58 & 25 & 52.08 & 4 & $8.33 \%$ \\
\hline Serum creatinine & 14 & 29.17 & 27 & 56.25 & 7 & $14.58 \%$ \\
\hline
\end{tabular}


recommendations given by three substantial guidelines on hypertensive disorders of pregnancy [21-23].

Our study was able to show that, according to the survey, the recommendations concerning follow-up care and risk management for patients affected by PE or HELLP syndrome, that are currently given by obstetricians in Austrian public hospitals are to a reasonable extent in line with current guidelines. Most specialists seem to be aware of and counsel patients on the association between PE and increased risk of long-term cardiovascular disease as well as the risk of recurrence. Regarding the evaluation of underlying chronic diseases such as thrombophilia or renal disease, as well as counselling on the future risk of renal disease there seems to be room for improvement according to our data. However, the overall long-term risk counselling after PE and HELLP syndrome has become well established in the hospital sector. The rising awareness in this area is certainly a consequence of numerous new insights on persistent long-term cardiac alterations and increased lifetime risk of essential hypertension, cardiovascular disease and stroke after PE [2, 24-27]. Various large observational studies have shown that follow-up and early interventions, including lifestyle modifications and patient education, are instrumental in risk reduction especially of CVD in women after pregnancy complicated by PE [28, 29]. To date, there is little knowledge on how these patients are currently managed postnatally. A recent qualitative study by Dijkhuis et al. exploring current opinions concerning follow-up for cardiovascular risks in Dutch women with a history of PE showed that follow-up has not been implemented in the north of the Netherlands [28]. Medical specialists were aware of the associated long-term risks of PE, however, the information

Table 3 Recommendations on the duration of postpartum blood pressure monitoring

\begin{tabular}{lrll}
\hline & $n$ & $\%$ (of all cases) & Valid \% \\
\hline $\begin{array}{l}\text { Postpartum blood pressure monitor- } \\
\text { ing }\end{array}$ & & & \\
6-8 weeks & 19 & 39.58 & $46.34 \%$ \\
3-6 months & 6 & 12.5 & $14.63 \%$ \\
Until normal blood pressure values & 7 & 14.58 & $17.07 \%$ \\
$\quad$ Depending on blood pressure & 1 & 2.08 & $2.44 \%$ \\
$\quad$ values & & & \\
Life-long & 7 & 14.58 & $17.07 \%$ \\
In case of antihypertensive treat- & 1 & 2.08 & $2.44 \%$ \\
$\quad$ ment & & & \\
$\quad$ Postpartum blood pressure moni- & 1 & 2.08 & - \\
$\quad$ toring not recommended & & & - \\
$\quad$ Not mentioned & 6 & 12.5 & - \\
$\quad$ Total (missing answers) & 7 & 14.58 & - \\
$\quad$ Total & 48 & 100 & \\
\hline
\end{tabular}

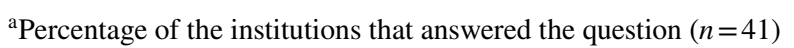

provided to patients was minimal and inconsistent. This was generally not in line with our findings, as we were able to show that Austrian obstetricians gave a fairly high number of recommendations on risk management and follow-up care to patients after HDP concerning long-term risk of CVD, risk of recurrence and lifestyle modification. However, our observations showed a lack of counselling regarding the long-term risk of renal disease and assessment of underlying diseases such as thrombophilia. Bick et al. [16] conducted a study in the United Kingdom in which they interviewed a group of clinicians on their views and experiences on postnatal management of women who had HDP and their awareness of relevant NICE guideline recommendations $[22,30]$ on this issue. Their analysis highlighted several barriers in the implementation of the guidelines including poor compliance and lack of awareness of patients as well as lack of postnatal care plans. According to our data, however, physicians are updated on current guidelines on follow-up care for women with a history of PE and these seem to be reasonably implemented in clinical routine. The importance of counselling on lifestyle modifications, specifically weight management is also stressed, which was in line with the recommendations given by clinicians in Austrian obstetric departments. Melchiorre et al. [14] presented reasonable evidence to support the implementation of screening for cardiovascular disease as early as 1 year after delivery. Recommendations on the exact timing of follow-up of CVD as well as specified prevention strategies, however, have not yet been included in current guidelines and were not subject to our survey.

Despite the rising awareness of long-term risks of HDP, data on actual postpartum risk management and follow-up care after HDP are scarce. This study is the first to explore recommendations on follow-up care after PE in Austria. It, however, evaluated the awareness and recommendations of obstetric departments in public hospitals only, not investigating follow-up care in an outpatient setting, in the private sector or at general practitioners (GP). Considering the fact that patients are frequently referred to an outpatient setting or their GP for further care, an evaluation of follow-up care in this sector would be of high value. Our study had some limitations. The number of participants was rather small as the number of public obstetric departments in Austria (69) is limited. Nevertheless, in consideration of the percentage of participating clinics (69.6\%), we believe that our survey is representative for the current follow-up care and long-term risk counselling after HDP in Austrian public obstetric departments. In consideration of the study design, one cannot completely exclude that respondents may have been influenced by the tendency to agree with the questions (acquiescence bias) or answered questions to fit the interpretation of the survey (demand characteristics).

Postpartum care of women after a pregnancy complicated by PE or HELLP syndrome continues to be an area of low 
priority and resources. Future studies should investigate the impact of timely preventive intervention in improving cardiovascular health in this group of young women at risk. Furthermore, the implementation of structured screening for cardiovascular and renal disease as well as screening for underlying diseases after a pregnancy complicated by HDP should be promoted. Recommendations on the exact timing of follow-up as well as specified prevention strategies should be included in international and national guidelines. Additionally, more detailed education of women affected by HDP about later-life health risks and involvement in decisions about ongoing care should be encouraged as it could increase compliance and in consequence improve their outcome. More in depth research, especially in the outpatient sector is warranted to substantiate our findings and to implement standardized postnatal services in the hospital sector as well as in an outpatient setting. To reduce the discussed long-term risks as well as the risk of recurrence and to increase life expectancy for patients after a pregnancy affected by HDP, adequate counselling and follow-up care on the basis of evidence-based guidelines is indispensable in an outpatient setting.

\section{Conclusion}

Our study was able to show that postpartum counselling conducted by obstetricians concerning risk management after HDP has been largely established in the public hospital sector, however, showing deficits in follow-up care regarding the evaluation of underlying chronic diseases such as thrombophilia or renal disease, as well as counselling on the future risk of renal disease. Furthermore, our research highlights that exact recommendations concerning timing and strategies of follow-up after PE, as well as structured screening especially for cardiovascular diseases, need to be included in international and national guidelines and implemented into clinical routine to establish adequate follow-up care and improve long-term cardiovascular outcome for this young high-risk population. Additionally, evaluation of follow-up care and long-term risk counselling after PE and HELLP syndrome in the outpatient and private sector is necessary to support our findings and improve the implementation of postnatal services concerning follow-up care and risk management.

Supplementary Information The online version contains supplementary material available at https://doi.org/10.1007/s00404-021-06181-w.

Author contribution PP: data collection and management, data analysis, manuscript writing/editing; CB: project development, data collection; HZ: project development; BK: data analysis; PP: project development, manuscript editing; JB: project development, data collection, manuscript editing.
Funding Open access funding provided by Medical University of Vienna.

\section{Declarations}

Conflict of interest All the authors declare that they have no conflict of interest.

Code availability Not applicable.

Open Access This article is licensed under a Creative Commons Attribution 4.0 International License, which permits use, sharing, adaptation, distribution and reproduction in any medium or format, as long as you give appropriate credit to the original author(s) and the source, provide a link to the Creative Commons licence, and indicate if changes were made. The images or other third party material in this article are included in the article's Creative Commons licence, unless indicated otherwise in a credit line to the material. If material is not included in the article's Creative Commons licence and your intended use is not permitted by statutory regulation or exceeds the permitted use, you will need to obtain permission directly from the copyright holder. To view a copy of this licence, visit http://creativecommons.org/licenses/by/4.0/.

\section{References}

1. Organization WH (2013) Women's health. Fact sheet No. 334. WHO, Geneva

2. van Rijn BB, Nijdam M-E, Bruinse HW, Roest M, Uiterwaal CS, Grobbee DE, Bots ML, Franx A (2013) Cardiovascular disease risk factors in women with a history of early-onset preeclampsia. Obstet Gynecol 121(5):1040-1048. https://doi.org/10.1097/AOG. 0b013e31828ea3b5

3. Spaan J, Peeters L, Spaanderman M, Brown M (2012) Cardiovascular risk management after a hypertensive disorder of pregnancy. Hypertension 60(6):1368-1373. https://doi.org/10.1161/hyper tensionaha.112.198812

4. Hutcheon JA, Lisonkova S, Joseph KS (2011) Epidemiology of pre-eclampsia and the other hypertensive disorders of pregnancy. Best Pract Res Clin Obstet Gynaecol 25(4):391-403. https://doi. org/10.1016/j.bpobgyn.2011.01.006

5. Melchiorre K, Sharma R, Thilaganathan B (2014) Cardiovascular implications in preeclampsia: an overview. Circulation 130(8):703-714. https://doi.org/10.1161/circulationaha.113. 003664

6. Melchiorre K, Sutherland GR, Baltabaeva A, Liberati M, Thilaganathan B (2011) Maternal cardiac dysfunction and remodeling in women with preeclampsia at term. Hypertension 57(1):85-93. https://doi.org/10.1161/hypertensionaha.110.162321

7. Melchiorre K, Sutherland G, Sharma R, Nanni M, Thilaganathan B (2013) Mid-gestational maternal cardiovascular profile in preterm and term pre-eclampsia: a prospective study. BJOG 120(4):496-504. https://doi.org/10.1111/1471-0528.12068

8. Bellamy L, Casas JP, Hingorani AD, Williams DJ (2007) Preeclampsia and risk of cardiovascular disease and cancer in later life: systematic review and meta-analysis. BMJ 335(7627):974. https://doi.org/10.1136/bmj.39335.385301.BE

9. Gagliardi G, Tiralongo GM, LoPresti D, Pisani I, Farsetti D, Vasapollo B, Novelli GP, Andreoli A, Valensise H (2017) Screening for pre-eclampsia in the first trimester: role of maternal hemodynamics and bioimpedance in non-obese patients. Ultrasound Obstet Gynecol 50(5):584-588. https://doi.org/10.1002/uog.17379 
10. Smith GC, Pell JP, Walsh D (2001) Pregnancy complications and maternal risk of ischaemic heart disease: a retrospective cohort study of 129,290 births. Lancet 357(9273):2002-2006. https://doi. org/10.1016/s0140-6736(00)05112-6

11. Paauw Nina D, Luijken K, Franx A, Verhaar Marianne C, Lely AT (2016) Long-term renal and cardiovascular risk after preeclampsia: towards screening and prevention. Clin Sci 130(4):239-246. https://doi.org/10.1042/cs20150567

12. Lykke JA, Langhoff-Roos J, Sibai BM, Funai EF, Triche EW, Paidas MJ (2009) Hypertensive pregnancy disorders and subsequent cardiovascular morbidity and type 2 diabetes mellitus in the mother. Hypertension 53(6):944-951. https://doi.org/10.1161/ HYPERTENSIONAHA.109.130765

13. Wang IK, Muo CH, Chang YC, Liang CC, Chang CT, Lin SY, Yen TH, Chuang FR, Chen PC, Huang CC, Wen CP, Sung FC, Morisky DE (2013) Association between hypertensive disorders during pregnancy and end-stage renal disease: a population-based study. CMAJ 185(3):207-213. https://doi.org/10.1503/cmaj. 120230

14. Melchiorre K, Thilaganathan B, Giorgione V, Ridder A, Memmo A, Khalil A (2020) Hypertensive disorders of pregnancy and future cardiovascular health. Front Cardiovasc Med 7:59. https:// doi.org/10.3389/fcvm.2020.00059

15. Melchiorre K, Sutherland GR, Liberati M, Thilaganathan B (2011) Preeclampsia is associated with persistent postpartum cardiovascular impairment. Hypertension 58(4):709-715. https://doi.org/ 10.1161/HYPERTENSIONAHA.111.176537

16. Bick D, Silverio SA, Bye A, Chang YS (2020) Postnatal care following hypertensive disorders of pregnancy: a qualitative study of views and experiences of primary and secondary care clinicians. BMJ Open 10(1):e034382. https://doi.org/10.1136/bmjop en-2019-034382

17. Bushnell C, McCullough LD, Awad IA, Chireau MV, Fedder WN, Furie KL, Howard VJ, Lichtman JH, Lisabeth LD, Piña IL, Reeves MJ, Rexrode KM, Saposnik G, Singh V, Towfighi A, Vaccarino $\mathrm{V}$, Walters MR (2014) Guidelines for the prevention of stroke in women. Stroke 45(5):1545-1588. https://doi.org/10.1161/01.str. 0000442009.06663.48

18. Piepoli MF, Hoes AW, Agewall S, Albus C, Brotons C, Catapano AL, Cooney M-T, Corrà U, Cosyns B, Deaton C, Graham I, Hall MS, Hobbs FDR, Løchen M-L, Löllgen H, Marques-Vidal P, Perk J, Prescott E, Redon J, Richter DJ, Sattar N, Smulders Y, Tiberi M, van der Worp HB, van Dis I, Verschuren WMM, Binno S, Group ESD (2016) 2016 European Guidelines on cardiovascular disease prevention in clinical practice: The Sixth Joint Task Force of the European Society of Cardiology and other societies on cardiovascular disease prevention in clinical practice (constituted by representatives of 10 societies and by invited experts) developed with the special contribution of the European Association for Cardiovascular Prevention and Rehabilitation (EACPR). Eur Heart J 37(29):2315-2381. https://doi.org/10.1093/eurheartj/ehw106

19. Maas A (2017) Screening after hypertensive pregnancy disorders: she can do best. Eur J Prev Cardiol 24:1733-1734

20. Mosca L, Benjamin EJ, Berra K, Bezanson JL, Dolor RJ, LloydJones DM, Newby LK, Piña IL, Roger VL, Shaw LJ, Zhao D, Beckie TM, Bushnell C, D'Armiento J, Kris-Etherton PM, Fang J, Ganiats TG, Gomes AS, Gracia CR, Haan CK, Jackson EA, Judelson DR, Kelepouris E, Lavie CJ, Moore A, Nussmeier NA, Ofili E, Oparil S, Ouyang P, Pinn VW, Sherif K, Smith SC Jr,
Sopko G, Chandra-Strobos N, Urbina EM, Vaccarino V, Wenger NK (2011) Effectiveness-based guidelines for the prevention of cardiovascular disease in women-2011 update: a guideline from the American Heart Association. Circulation 123(11):1243-1262. https://doi.org/10.1161/CIR.0b013e31820faaf8

21. Stepan H, Kuse-Föhl S, Klockenbusch W, Rath W, Schauf B, Walther T, Schlembach D (2015) Diagnosis and treatment of hypertensive pregnancy disorders: guideline of DGGG (S1-Level, AWMF Registry No. 015/018, December 2013). Geburtshilfe Frauenheilkd 75(9):900-914. https://doi.org/10.1055/s-00351557924

22. Redman CWG (2011) Hypertension in pregnancy: the NICE guidelines. Heart. https://doi.org/10.1136/heartjnl-2011-300949

23. Hypertension in pregnancy. Report of the American College of Obstetricians and Gynecologists' Task Force on Hypertension in Pregnancy (2013). Obstet Gynecol 122 (5):1122-1131. https:// doi.org/10.1097/01.AOG.0000437382.03963.88

24. Auger N, Potter BJ, He S, Healy-Profitós J, Schnitzer ME, Paradis G (2020) Maternal cardiovascular disease 3 decades after preterm birth: longitudinal cohort study of pregnancy vascular disorders. Hypertension 75(3):788-795. https://doi.org/10.1161/hypertensi onaha.119.14221

25. Wu P, Haththotuwa R, Kwok CS, Babu A, Kotronias RA, Rushton C, Zaman A, Fryer AA, Kadam U, Chew-Graham CA, Mamas MA (2017) Preeclampsia and future cardiovascular health: a systematic review and meta-analysis. Circ Cardiovasc Qual Outcomes. https://doi.org/10.1161/circoutcomes.116.003497

26. Heida KY, Bots ML, de Groot CJ, van Dunné FM, Hammoud NM, Hoek A, Laven JS, Maas AH, Roeters van Lennep JE, Velthuis BK, Franx A (2016) Cardiovascular risk management after reproductive and pregnancy-related disorders: a Dutch multidisciplinary evidence-based guideline. Eur J Prev Cardiol 23(17):18631879. https://doi.org/10.1177/2047487316659573

27. Lagerweij G, Brouwers L, De Wit G, Moons K, Benschop L, Maas A, Franx A, Wermer M, van Lennep JR, van Rijn B, Koffijberg $H$ (2013) Impact of preventive screening and lifestyle interventions in women with a history of preeclampsia: a micro-simulation study. Eur J Prev Cardiol 204:74. https://doi.org/10.1177/20474 87319898021

28. Dijkhuis TE, Bloem F, Kusters LAJ, Roos SM, Gordijn SJ, Holvast F, Prins JR (2020) Investigating the current knowledge and needs concerning a follow-up for long-term cardiovascular risks in Dutch women with a preeclampsia history: a qualitative study. BMC Pregnancy Childbirth 20(1):486. https://doi.org/10.1186/ s12884-020-03179-1

29. Smith GN, Louis JM, Saade GR (2019) Pregnancy and the postpartum period as an opportunity for cardiovascular risk identification and management. Obstet Gynecol 134(4):851-862. https:// doi.org/10.1097/aog.0000000000003363

30. Webster K, Fishburn S, Maresh M, Findlay SC, Chappell LC (2019) Diagnosis and management of hypertension in pregnancy: summary of updated NICE guidance. BMJ 366:15119. https://doi. org/10.1136/bmj.15119

Publisher's Note Springer Nature remains neutral with regard to jurisdictional claims in published maps and institutional affiliations. 